\title{
Effect of Carboxyl Functionalized MWCNTs on the Cure Behavior of Epoxy Resin
}

\author{
Nusrat Jahan ${ }^{1}$, Alfred-Tcherbi Narteh ${ }^{2}$, Mahesh Hosur ${ }^{2}$, Muhammad Rahman ${ }^{1}$, Shaik Jeelani ${ }^{1,2}$ \\ ${ }^{1}$ Mechanical Engineering, Tuskegee University, Tuskegee, USA; ${ }^{2}$ Materials Science and Engineering, Tuskegee University, Tuske- \\ gee, USA. \\ Email: hosur@mytu.tuskegee.edu
}

Received January $22^{\text {nd }}, 2013$; revised February $22^{\text {nd }}, 2013$; accepted March $20^{\text {th }}, 2013$

Copyright (C) 2013 Nusrat Jahan et al. This is an open access article distributed under the Creative Commons Attribution License, which permits unrestricted use, distribution, and reproduction in any medium, provided the original work is properly cited.

\begin{abstract}
Effects of carboxyl functionalized MWCNTs on the cure behavior of epoxy resin (EPIKOTE ${ }^{\mathrm{TM}}$ resin $^{862}$ and EPICURE $^{\mathrm{TM}}$ curing agent $\mathrm{W}$ ) were investigated by using differential scanning calorimeter in dynamic scan mode. Results indicated that nanotubes could initiate cure reaction at lower temperature while only $0.1 \mathrm{wt} \%$ samples were able to suppress the peak temperature $\left(T_{p}\right)$ consistently regardless of different heating rate due to their higher reaction rate, other two batches $(0.2 \mathrm{wt} \%$ and $0.3 \mathrm{wt} \% \mathrm{CNT})$ showed hardly any change in $T_{p}$ compared to neat samples. Furthermore, addition of small amount $(0.1 \mathrm{wt} \%)$ of CNTs significantly reduced the activation energy of the system but further addition elevated that due to their retarding effect. Also, a correlation was established between the dispersion state of CNTs in epoxy and total heat of reaction $(\Delta \mathrm{H})$ where lower $\Delta \mathrm{H}$ was considered as an indication of better interfacial interaction of CNTs with matrix and hence, better dispersion. The difference in curing behavior of three different CNT percentages was discussed in terms of their steric hindrance and state of dispersion in the matrix.
\end{abstract}

Keywords: Carbon Nanotubes; DSC; Steric Hindrance; Peak Temperature; Activation Energy

\section{Introduction}

Owing to their unique structural integrity, carbon nanotubes (CNTs) have emerged as potential reinforcements because of their outstanding thermal, mechanical and electrical properties [1-5]. Higher specific surface area along with better stress transfer capability has made them an ideal candidate for high performance composite in structural application. Naturally, researchers have gone through a number of attempts to enhance the properties of polymer materials by incorporating CNTs. In most cases, these new composites, incorporated with CNTs exhibit excellent thermal, mechanical and electrical properties. Although numerous works have been reported on developing CNT incorporated polymeric composites, translation of properties is yet well below the theoretical expectation.

Among the various thermosetting polymers, epoxy is one of the most popular resins utilized in various industrial applications. Epoxies have found their application in coating, adhesive, aerospace and electronics industries [6-8] because of their excellent mechanical and chemical properties as well as high heat distortion temperature. The superior mechanical and chemical properties possessed by the epoxy polymer are a result of curing reaction, in which a low molecular weight resin is converted to an infinite molecular weight polymer with a three-dimensional network structure through chemical reaction or physical interlocking or both. A wide range of curing agents like aliphatic or aromatic amines, anhydrides etc. are used to initiate the cure reaction. CNTs in epoxy not only improve the load bearing and heat resistant capacity but also affect the curing process through different mechanism and alter the ultimate properties of final composites.

Even though the CNT incorporated epoxy composites have shown improvement in mechanical properties but it is not to the same degree in various studies [9-12]. For example, Allaoui et al. [9] found that $1 \mathrm{wt} \%$ CNT improved the young's modulus by $100 \%$ whereas Zhu et al. [10] found only a moderate improvement adding the same quantity. This variation may be attributed to the state of dispersion, orientation of CNT particles as well as the interface between the particle and the matrix. Though dispersion is regarded as one of the prerequisite to fabricate composite, there is no reasonable way to evaluate it over the whole specimen. In most recent efforts, optical microscope, scanning electron microscope 
and transmission electron microscope image analysis have been employed though the image shows only very small cross-section of whole sample.

Study of cure behavior of epoxy composites is of significant importance for design and analysis of processing parameters. Meanwhile, numerous studies have been conducted on cure kinetics using the differential scanning calorimeter (DSC) where it has been observed that cure kinetics can change when CNTs are added in the resin. Some studies showed that addition of CNTs can act as a catalyst [8] whereas some studies revealed the retarding effect of CNTs on cure reaction [7,13,14]. Tao et al. [7] studied the effect of three different CNTs on epoxy curing behavior and found that addition of CNTs lowers the total heat of reaction as well as decreases the overall degree of cure. Yang et al. [15] found that amine group on the surface of MWCNTs has a retarding effect when added at low concentration as compared to neat epoxy but at higher loading, CNTs significantly lowered the activation energy of the system. Abdalla et al. [13] found that while addition of fluorinated MWCNTs had hardly any effect on activation energy of the epoxy system, carboxylated CNTs increased the activation energy of the system hence, lowered the degree of cure. Zhou et al. [14] also found that addition of CNTs reduced the overall degree of cure. Kim et al. [16] interestingly found a correlation between the concentration of well dispersed CNTs and the total heat of reaction. From the above mentioned observations, it is possible that CNTs can hinder the cure reaction, hence, affect the total heat of reaction and this issue might be correlated with their dispersion state in the matrix since uniformly dispersed CNTs are up for this hindrance. Therefore, the relation between the cure kinetics and heat of reaction can lead a way of assessing the dispersion state.

In this study, cure behavior of various percentages CNT modified composites was observed through total heat of reaction, cure initiation temperature, peak temperature and activation energy using differential scanning calorimetry in dynamic scan mode. Based on the literature study of various dispersion techniques and their effect on mechanical and thermal properties of epoxy composites, a combination method of sonication and magnetic stirring along with a solvent (acetone) was chosen as the dispersion route. Based on the result, a correlation was established between the dispersibility of CNTs and total heat of reaction.

\section{Materials, Sample Preparation and Characterization}

\subsection{Materials}

The primary materials used in this study are carboxyl functionalized multi-walled carbon nanotubes, an epoxy resin and a high strength carbon fiber. Carbon nanotubes used in this study were $\mathrm{COOH}$ - functionalized multiwalled carbon nanotubes synthesized by catalytic chemical vapor deposition (CCVD) method and procured from Nanocyl Inc. The nanotubes were supplied with an average diameter of $9.5 \mathrm{~nm}$ and average length of less than $1.5 \mu \mathrm{m}$. Carbon purity was ensured as greater than $95 \%$ and concentration of functional group was less than $4 \%$ as reported by the supplier. The resin used in the study was a two part epoxy (part A: epoxy (Epon 862) and part B: curing agent). The epoxy was diglycidyl ether of bisphenol $\mathrm{F}$ and the curing agent was EpiCure $\mathrm{W}$ (aromatic diamine) supplied by Miller-Stephenson Chemical Co. The solvent, acetone was purchased from Fibre Glast Developments Corporation, USA.

\subsection{Sample Preparation}

First, pre-calculated amount of MWCNTs $(0.1 \mathrm{wt} \%, 0.2$ $\mathrm{wt} \%$ or $0.3 \mathrm{wt} \%$ ) were physically mixed with $30 \mathrm{~mL}$ acetone in a beaker. Probe sonication was used to disperse the MWCNTs in acetone for $30 \mathrm{~min}$. During the sonication process, beaker was placed in a cooling bath to resist heating up the beaker. This was because, heat produced during the process at the sonication probe may cause local agglomerations of MWCNTs [17]. At the same time, pre-calculated amount of epoxy (part A) was heated at $70^{\circ} \mathrm{C}$ to reduce the viscosity of the resin to ensure proper wetting of both nano and micro filler. After finishing sonication, MWCNT/acetone mixture was added to heated resin, manually mixed, and sonicated further for $1 \mathrm{hr}$. Upon completion of the sonication process, MWCNT/acetone/epoxy mixture was then mixed with curing agent and placed on a hot plate set to a temperature of $70^{\circ} \mathrm{C}$. A magnetic bar was placed in the beaker and set to rotate at a speed of $1000 \mathrm{rpm} 3 \mathrm{hr}$. The stoichiometric ratio of epoxy (Epon 862) and EpiCure W was 100:26.4, as suggested by the manufacturer. The mixture was then placed in a vacuum oven at $60^{\circ} \mathrm{C}$ for 2 hours to ensure complete removal of both the entrapped bubbles and acetone as soon as stirring get to finish. Then, $10 \mathrm{mg}$ of this modified resin was taken in aluminum hermetic pan and placed in calorimeter in dynamic scan using four different heating rates $(2,5,10$ and 15 $\mathrm{deg} / \mathrm{min})$. Neat sample was also prepared following the same procedure.

\subsection{Characterization Techniques}

Differential Scanning Calorimetry (DSC) is an advanced technique to measure the heat flow through a sample whatever the sample is heated at a controlled rate or in isothermal condition. The amount of heat flow is dependent on sample morphology. DSC test was carried out using a TA instrument $\mathrm{Q} 1000$ in dynamic mode using four different heating rates: $2^{\circ} \mathrm{C} / \mathrm{min}, 5^{\circ} \mathrm{C} / \mathrm{min}, 10^{\circ} \mathrm{C} / \mathrm{min}$, 
$15^{\circ} \mathrm{C} / \mathrm{min}$. For dynamic scan, $10 \mathrm{mg}$ of uncured sample was heated from $30^{\circ} \mathrm{C}$ to $400^{\circ} \mathrm{C}$ for each specific heating rate. All DSC tests were run using aluminum hermetic sample pans and $50 \mathrm{~mL} / \mathrm{min}$ of $\mathrm{N}_{2}$ purge. Upward peaks were considered exothermic for all DSC thermograms. Total heat of reaction, cure initiation and peak temperature were calculated from the heat flow curve. Also, the activation energy of each system for different degree of cure was estimated to observe the overall effect of CNTs on the system.

\section{Results and Discussion}

\section{Cure Behavior of Epoxy Composite by DCS Dynamic Scan}

The dynamic DSC thermograms for pure epoxy and MWCNT modified epoxy nanocomposites at four different heating rates from $2^{\circ} \mathrm{C} / \mathrm{min}-15^{\circ} \mathrm{C} / \mathrm{min}$ has been shown in Figure 1. To characterize a polymer, it is necessary to determine if there are any overlapping transitions. Since transitions like evaporation, cure, decomposition etc. are kinetic events i.e. they are a functions of both time and temperature, higher heating rates will shift the transitions to a higher temperature because the epoxy gets less time for transitioning at any specific temperature. Thus, higher heating rate increases the sensitivity and lower heating rate increases the resolution since samples get enough time to transition at a specific temperature. That is why, in this study a range of heating rates were used not only to increase the resolution of any transition peak but also to detect any overlapping transitions and activation energies during overall cure reaction.

As shown in figure, there is only one exothermic peak for all four type of specimen. Also, presence of CNTs in epoxy lowers the exothermic peak height than that of neat epoxy which indicates increased degree of interacttion of MWCNTs with epoxy resin as well as physical hindrance by nanotubes to the polymer chain mobility. The effect of CNT concentration on epoxy can be verified by checking the total heat of reaction $(\Delta \mathrm{H})$, onset temperature $\left(T_{i}\right)$ and peak temperature $\left(T_{p}\right)$. All these data have been summarized in Table 1. It can be seen from the Table, heat of reaction decreases with increasing heating rate for each system. Also, CNT concentration leads to a reduction in total heat of reaction up to 0.2 $\mathrm{wt} \%$ loading beyond which $\Delta \mathrm{H}$ goes up. As per earlier discussion, well dispersed CNTs can act as physical obstruction to the mobility of polymeric chain and lower mobility of polymeric molecule may result in the reduction of the total heat of reaction. On the other hand, aggregated CNTs are much less efficient in hindering polymer chain movement and have hardly any effect on the value of total heat of reaction [16].

Therefore, decrease in $\Delta \mathrm{H}$ value due to addition of up to $0.2 \mathrm{wt} \% \mathrm{CNT}$ can be attributed to the hindrance of

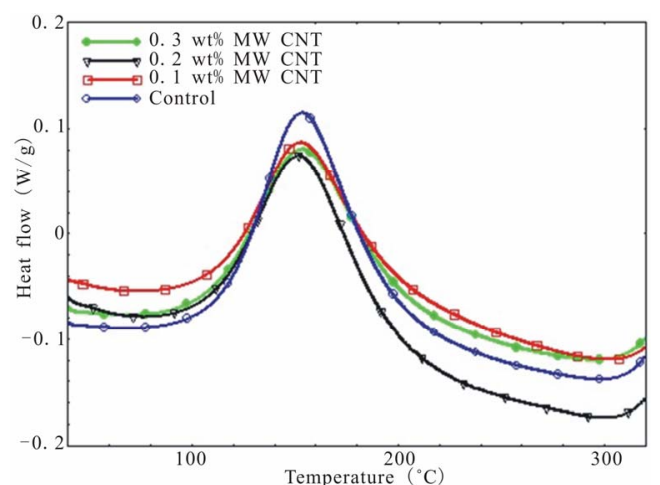

(a)

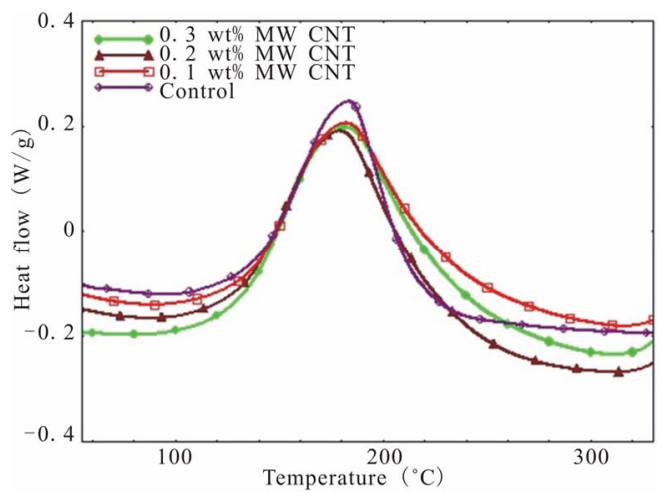

(b)

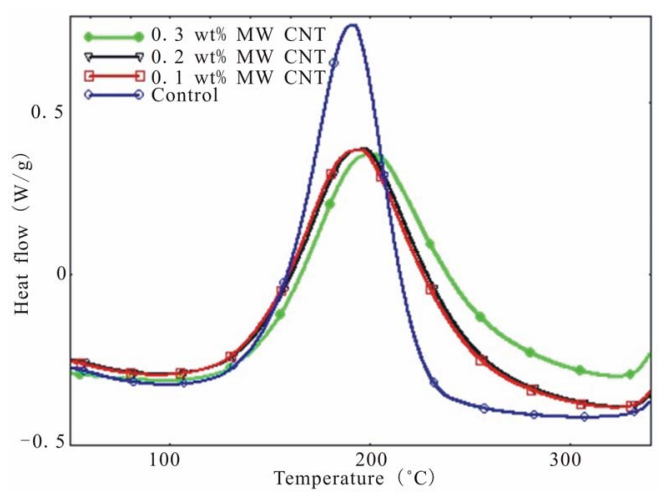

(c)

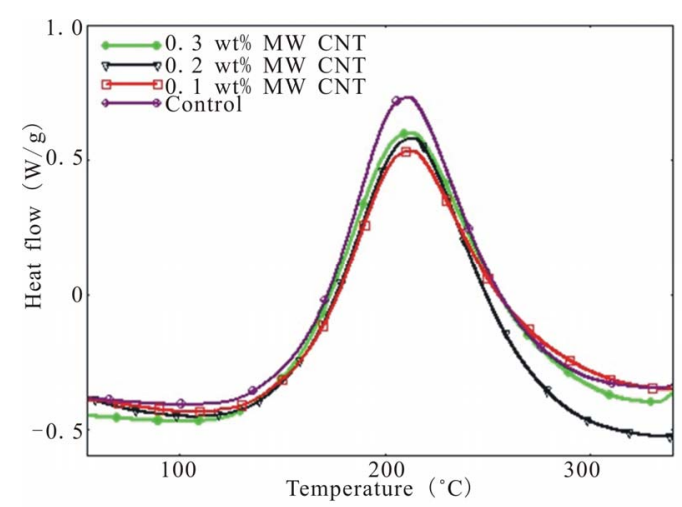

(d)

Figure 1. Dynamic DSC thermograms of different system at various heating rate (a) 2; (b) 5; (c) 10; and (d) $15 \mathrm{deg} / \mathrm{min}$. 
Table 1. Characteristics properties obtained from DSC dynamic scan.

\begin{tabular}{|c|c|c|c|c|}
\hline Sample ID & Heating rate $(\mathrm{deg} / \mathrm{min})$ & $\Delta \mathrm{H}$ & $T_{i}$ & $T_{p}$ \\
\hline \multirow{4}{*}{ Neat } & 2 & 421.2 & 118.3 & 157.05 \\
\hline & 5 & 376.6 & 134.47 & 182.05 \\
\hline & 10 & 323.5 & 148.54 & 199.9 \\
\hline & 15 & 321.4 & 158.86 & 208.51 \\
\hline \multirow{4}{*}{$0.1 \mathrm{wt} \% \mathrm{CNT}$} & 2 & 387.3 & 109.26 & 153.26 \\
\hline & 5 & 341.4 & 126.57 & 178.0 \\
\hline & 10 & 321.5 & 139.91 & 196.19 \\
\hline & 15 & 316.3 & 148.74 & 207.43 \\
\hline \multirow{4}{*}{$0.2 \mathrm{wt} \% \mathrm{CNT}$} & 2 & 359.2 & 1116.23 & 157.96 \\
\hline & 5 & 323.3 & 133.78 & 182.99 \\
\hline & 10 & 302.3 & 148.64 & 202.01 \\
\hline & 15 & 288.7 & 157.78 & 209.8 \\
\hline \multirow{4}{*}{$0.3 \mathrm{wt} \% \mathrm{CNT}$} & 2 & 367.6 & 112.6 & 157.47 \\
\hline & 5 & 383.3 & 128.85 & 182.45 \\
\hline & 10 & 304.2 & 144.65 & 202.01 \\
\hline & 15 & 328.9 & 153.86 & 210.81 \\
\hline
\end{tabular}

polymer chain mobility due to well dispersed CNTs whereas increase of $\Delta \mathrm{H}$ due to further addition of CNTs can be attributed to the presence of aggregated CNTs inefficiently participated in hindering polymer chain movement. Also, onset temperature for curing is lowest for $0.1 \mathrm{wt} \%$ CNT loaded samples followed by $0.3 \mathrm{wt} \%$ and $0.2 \mathrm{wt} \% \mathrm{CNT}$ incorporated composites indicating that CNTs can facilitate the curing initially by lowering the onset temperature where $0.1 \mathrm{wt} \% \mathrm{CNT}$ demonstrates the most noticeable effect on lowering the onset temperature while the other two loading of CNT showed similar but more modest effect on $T_{i}$. Similar results have been observed by Tao et al. [7] for short SWCNT/HiPCo-SWCNT/XD-CNT infused DGEBF/DETA system.

The peak temperature $\left(T_{p}\right)$ increases with increasing heating rate. Small amount of CNTs $(0.1 \mathrm{wt} \%)$ causes slight decrease of peak temperature compared to neat epoxy because of their catalytic action but higher loading of CNTs $(0.2 \mathrm{wt} \%$ and $0.3 \mathrm{wt} \%)$ results greater peak temperature as shown in Table 1 which demonstrates the retardation effect of MWCNTs due to their steric hindrance [18].

Figure 2 represents the degree of conversion $(\alpha)$ as a function of temperature for neat epoxy and various MWCNT/epoxy nanocomposites at four different heating rates. As shown in figure, all the curves are in the sigmoidal form and only shift a distance along the tempera-

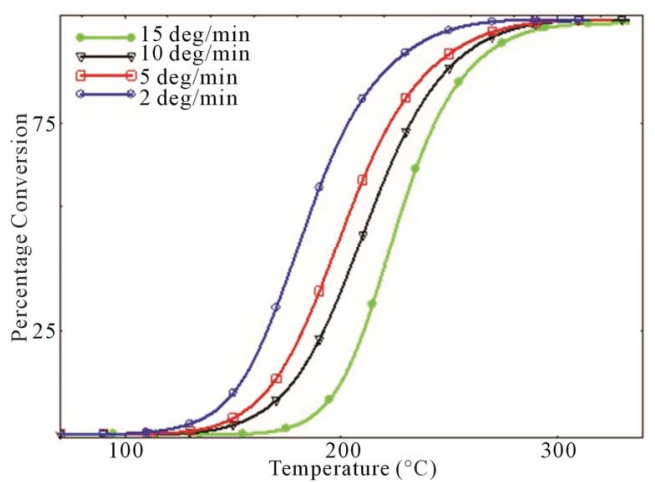

(a)

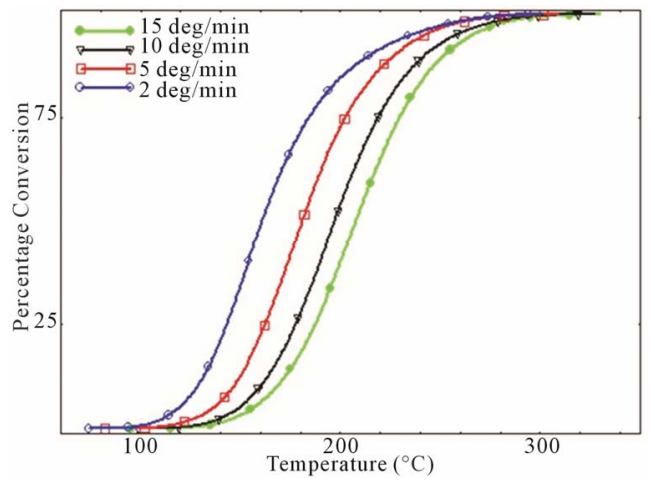

(b)

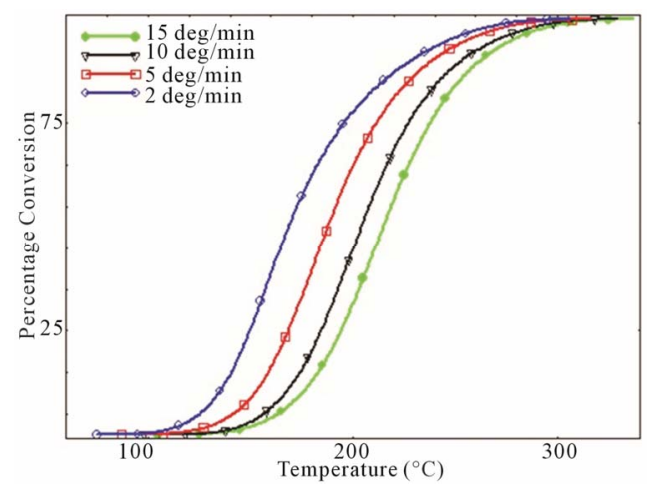

(c)

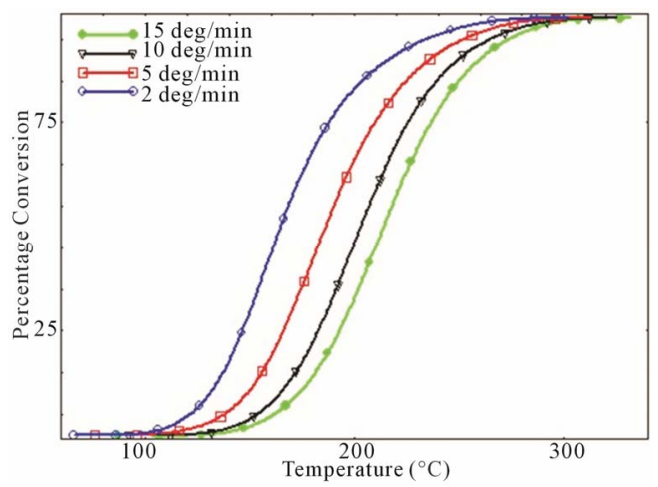

(d)

Figure 2. Degree of conversion as a function of temperature for various CNT added composites (a) Neat; (b) $0.1 \mathrm{wt} \%$; (c) $0.2 \mathrm{wt} \%$; and (d) $0.3 \mathrm{wt} \%$. 
ture axis with increasing heating rate which is an indication of the autocatalytic nature of cure reaction of all the studied system and in well agreement with earlier studies $[7,14]$. That is, incorporation of MWCNTs and their carboxyl groups on their surfaces does not change the cure reaction mechanism of DGEBF/DETDA system. Also, degree of conversion increases with decreasing heating rate for all the neat and nanophased composites.

Degree of conversion curves as a function of temperature of various studied systems at four different heating rates are shown in Figure 3. It is observed that for every different heating rate, small amount of CNTs such as 0.1 $\mathrm{wt} \%$ act like a catalyst by converting more epoxies into cured matrix whereas for higher percentage of CNTs, epoxy showed lower degree of conversion compared to neat epoxy system which implies that relative higher percentage of MWCNTs have significant retarding effect on curing characteristics of epoxy. This retarding behavior of CNTs might be attributed to the increasing surface area and tendency to form agglomerates at higher loading. A close look to Figure 3 reveals the cure inhibition effect due to increasing concentration of MWCNTs like $0.2 \mathrm{wt} \%-0.3 \mathrm{wt} \%$ MWCNT. For the development of laminated composites, cure retardation effect caused by the addition of MWCNTs could have some negative effect on the properties since it requires longer post curing time.

The activation energy of a cure reaction represents the potential barrier of that reaction. For the better understanding of cure behavior of DGEBF/MWCNT/DETA systems, study on activation energy is contributory. During a cure reaction, reaction rate $(\mathrm{d} \alpha / \mathrm{d} t)$ as a function of time $(t)$ was calculated from the heat flow in DSC dynamic scan by using Equation (1):

$$
\mathrm{d} \alpha / \mathrm{d} t=\mathrm{d} H / \mathrm{d} t=k(T) f(\alpha)
$$

where, $T$ is the temperature, $f(\alpha)$ is the reaction model and $k(T)$ is the rate constant which follows Arrhenius equation as in Equation (2):

$$
K(T)=A \exp \left(-E_{a} / R T\right)
$$

where $A$ is the pre exponential factor, $E_{a}$ is the activation energy and $R$ is the gas constant. From Equations (1) and (2) we get,

$$
\mathrm{d} \alpha / \mathrm{d} t=A \exp \left(-E_{a} / R T\right) f(\alpha)
$$

By taking natural logarithm on both sides,

$$
\ln (\mathrm{d} \alpha / \mathrm{d} t)=\ln (A f(\alpha))-E_{a} / R T
$$

Thus, the plot of $\ln (\mathrm{d} \alpha / \mathrm{d} t)$ versus $(1 / T)$ at the same $\alpha$ from a series of DSC thermograms at different heating rates would provide a straight line where the slope allows to determine the activation energy, $E_{a}$. Figure 4 represents the curves of $\ln (\mathrm{d} \alpha / \mathrm{d} t)$ versus $(1 / T)$ for neat epoxy

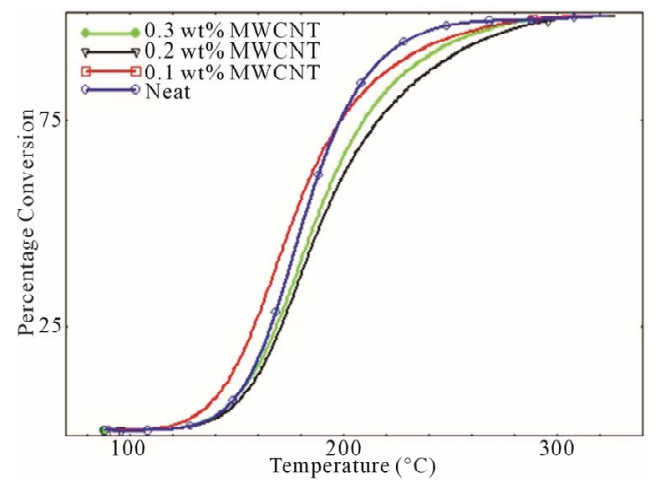

(a)

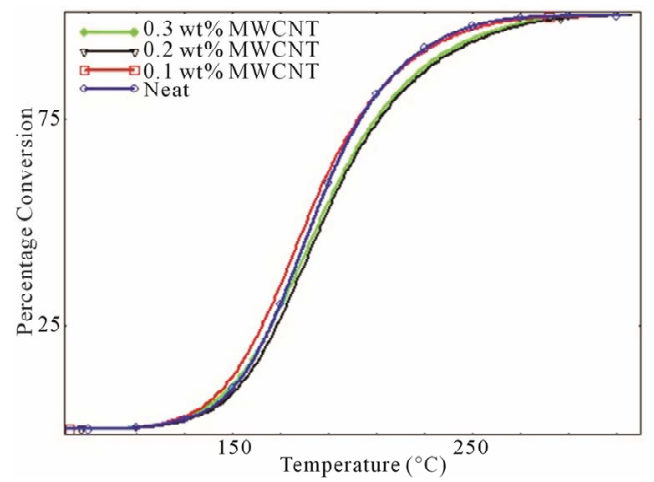

(b)

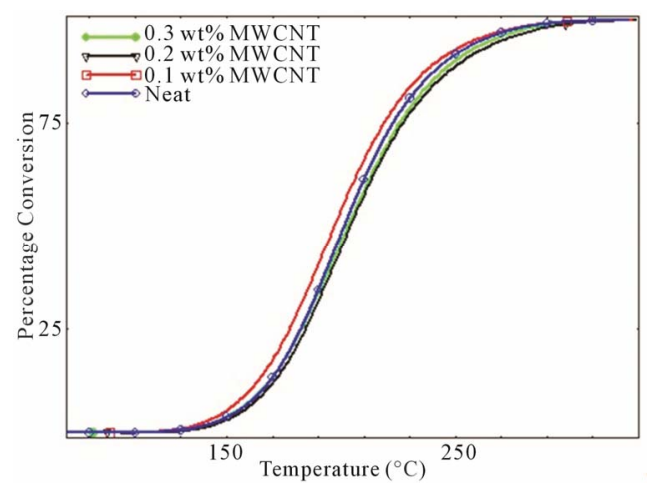

(c)

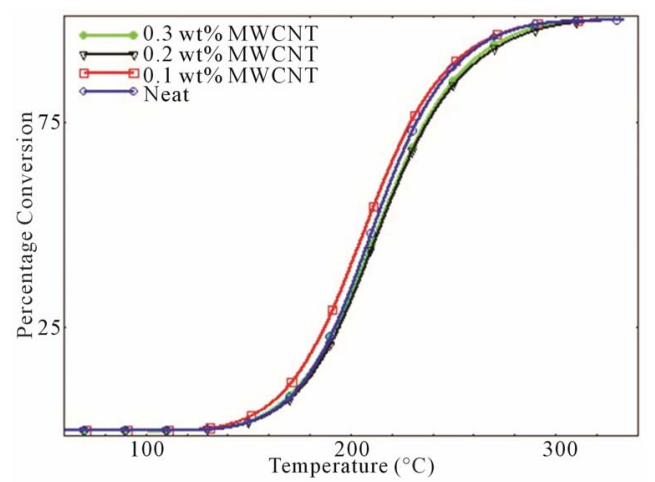

(d)

Figure 3. Degree of conversion as a function of temperature for various composites at different heating rate (a) 2; (b) 5; (c) 10; and (d) $15 \mathrm{deg} / \mathrm{min}$. 


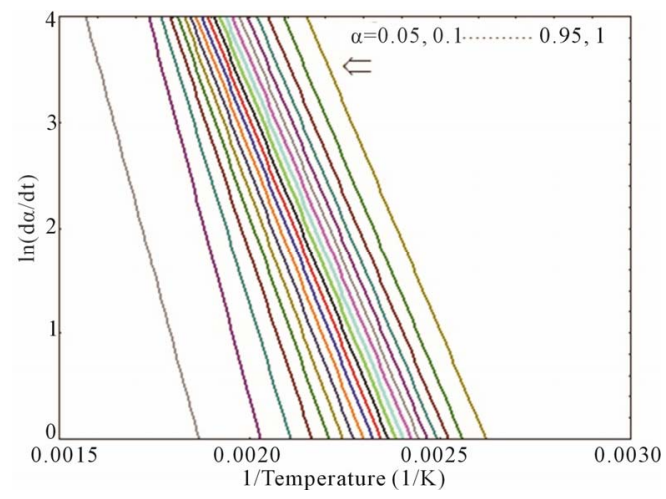

(a)

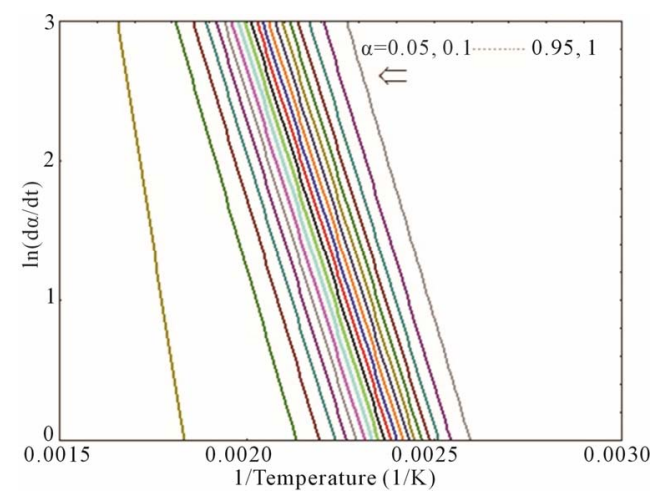

(b)

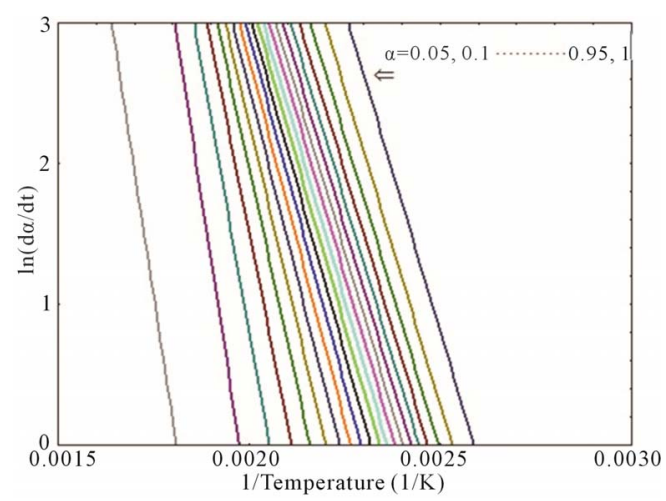

(c)

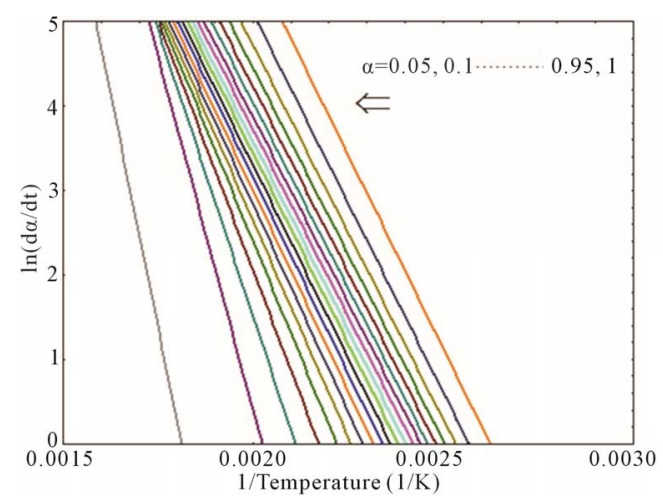

(d)

Figure 4. Plot of $\ln (\mathrm{d} \alpha / \mathrm{d} t)$ versus (1/T) for (a) neat; (b) 0.1 wt \%; (c) 0.2 wt \% and (d) 0.3 wt \% composites. and MWCNT/epoxy nanocomposites at different values of $\alpha(\alpha=0.05,0.1,0.15,0.2, \cdots 0.90,0.95$ and 1$)$. Activation energy $\left(E_{a}\right)$ as function of degree of cure $(\alpha)$ has been plotted as shown in Figure 5 for both neat and nanophased epoxy. Slope of the curve in Figure 4 was used for calculating the activation energy using Equation (4). As can be seen from the figure, CNTs can act as a catalyst when added at very low concentration like 0.1 $\mathrm{wt} \%$ and lowers the activation energy of the system. On the other hand, activation energy is higher for higher percentage of CNTs like $0.2 \mathrm{wt} \%, 0.3 \mathrm{wt} \%$ loading, which might be the fact that higher concentration of carboxyl groups on MWCNT surface hinders the curing process of the epoxy system. In other words, higher CNT loading contributes in increasing the activation energy which indicates that more carboxyl groups on the surface of MWCNTs might hinder $\mathrm{COOH}$ - epoxide reaction because of the electrostatic repulsion among the carboxyl groups obstructing the easier reaction path and effectively enhancing the influence of steric hindrance caused by the MWCNTs in the cure reaction [15]. The higher content of carboxyl groups significantly accelerates the interaction between CNTs and epoxy and thus, facilitates the occurrence of diffusion controlled vitrification process.

For all epoxy system, activation energy increases significantly beyond $80 \%$ conversion that is, $\alpha=0.80$ can be considered as the gel point of DGEBF/DETA system as shown by Qui et al. [8] for TGDDM/DDS system.

\section{Conclusion}

Effects of MWCNTs on the cure reaction of epoxy resin were examined via DSC. Curing behavior with four different temperatures was analyzed. It was found from DSC dynamic scan that addition of CNTs initiated the curing reaction at lower temperature but did not change

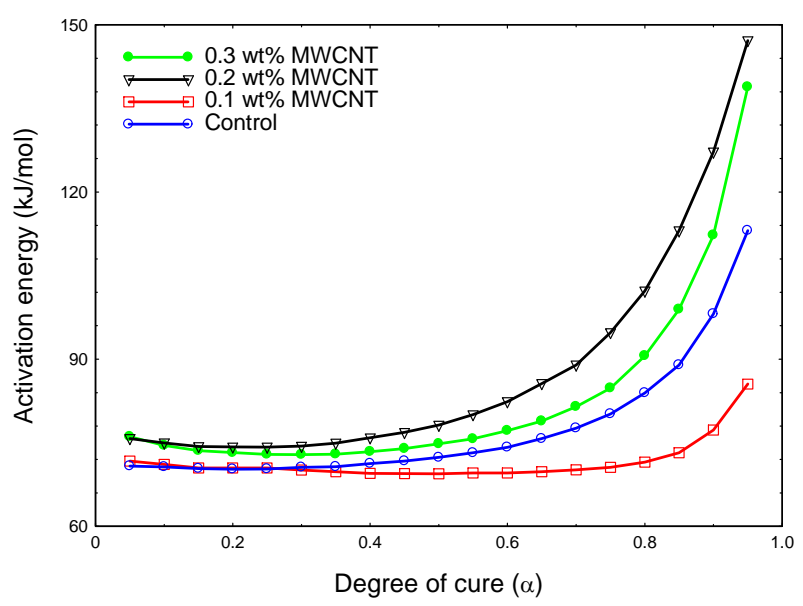

Figure 5. Activation energy as a function of degree of conversion for various composite systems. 
the autocatalytic cure reaction mechanism of the epoxy system by sustaining their sigmoidal shaped curve of percentage conversion vs. temperature. Also, CNTs significantly reduced the total heat of reaction by hindering the molecular movement of polymer chain. Additionally, from the plot of percentage conversion and activation energy, it is clear that very low loading of CNTs $(0.1$ $w \mathrm{t} \%$ ) can act as a catalyst and thus, facilitates the cure reaction but higher loading of CNTs $(0.2 \mathrm{wt} \%$ and 0.3 $\mathrm{wt} \%$ ) have retarding effects on the cure reaction, might be due to the higher specific surface area of CNTs. CNTs with high surface area cause higher electrostatic repulsion and greater steric hindrance on cure reaction which ultimately demands a higher post curing temperature during composite fabrication. Since the mixing method of CNTs in epoxy plays an important role in dispersion hence, in cure behavior, further investigation on mixing procedure should be carried out to add higher amount of CNTs in epoxy matrix.

\section{Acknowledgements}

Authors acknowledge the funding support from NSFEPSCoR (EPS-1158862), NASA-EPSCoR (NNX10 AN26A) and DoD (W911NF-12-1-0053).

\section{REFERENCES}

[1] C. U. Okoro, M. K. Hossain, M. V. Hosur and S. Jeelani, "Mechanical Characterization of XD-Grade Carbon Nanotube/Epon 862 Processed by Dual Phase Dispersion Technique," Journal of Engineering Materials and Technology, Vol. 133, No. 4, 2011, pp. 131-134. doi: $10.1115 / 1.4004692$

[2] F. H. Gojny, J. Nastalczyk, Z. Roslaniec and K. Schulte, "Surface Modified Multiwalled Carbon Nanotubes in CNT/ Epoxy-Composites," Chemical Physics Letters, Vol. 370, No. 5-6, 2003, pp. 820-824. doi:10.1016/S0009-2614(03)00187-8

[3] M. Hosur, R. Barua, S. Zainuddin, A. Kumar, J. Trovillion and S. Jeelani, "Effect of Processing Techniques on the Performance of Epoxy/MWCNT Nanocomposites," Journal of Applied Polymer Science, Vol. 127, No. 6, 2012, pp. 4211-4224. doi:10.1002/app.37990

[4] T.-W. Thostenson and E. T. Chou, "Aligned Multi-Walled Carbon Nano-Tube Reinforced Composites: Processing and Mechanical Characterization," Journal of Physics D: Applied Physics, Vol. 35, No. 16, 2002, pp. 77-80.

[5] M. Hosur, R. Barua, S. Zainuddin, A. Kumar, J. Trovillion and S. Jeelani, "Rheology, Flexure and Thermomechanical Characterization of Epoxy/CNF Nanocomposites: Effect of Dispersion Techniques," Polymers and Polymer Composites, Vol. 20, No. 6, 2012, pp. 505-518.

[6] S. K. Ooi, W. D. Cook, G. P. Simon and C. H. Such, "DSC Studies of the Curing Mechanisms and Kinetics of DGEBA Using Imidazole Curing Agents," Polymer, Vol.
41, No. 10, 2000, pp. 3639-3649. doi:10.1016/S0032-3861(99)00600-X

[7] K. Tao, S. Yang, J. C. Grunlan, Y.-S. Kim, B. Dang, Y. Deng, R. L. Thomas, B. L. Wilson and X. Wei, "Effects of Carbon Nanotube Fillers on the Curing Processes of Epoxy Resin-Based Composites," Journal of Applied Polymer Science, Vol. 102, No. 6, 2006, pp. 5248-5254. doi:10.1002/app. 24773

[8] S. L. Qiu, C. S. Wang, Y. T. Wang, C. G. Liu, H. F. Chen, X. Y. Xie, Y. A. Huang and R. S. Cheng, "Effects of Graphene Oxides on the Cure Behaviors of a Tetrafunctional Epoxy Resin," eXPRESS Polymer Letters, Vol. 5, No. 9, 2011, pp. 809-818.

[9] A. Allaoui, S. Bai, H. Cheng and J. Bai, "Mechanical and Electrical Properties of a MWNT/epoxy Composite," Composites Science and Technology, Vol. 62, No. 15, 2002, pp. 1993-1998. doi:10.1016/S0266-3538(02)00129-X

[10] J. Zhu, H. Rodriguez-Macias, J. L. Margrave, V. N. Khabashesku, A. M. Imam, K. Lozano and E. V. Barrera, "Reinforcing Epoxy Polymer Composites through Covalent Integration of Functionalized Nanotubes," Advanced Functional Materials, Vol. 14, 2004, pp. 643-648. doi:10.1002/adfm.200305162

[11] F. Gojny, M. Wichmann, U. Kopke, B. Fiedler, K. Schulte, "Carbon Nanotube-Reinforced Epoxy-Composites: Enhanced Stiffness and Fracture Toughness at Low Nanotube Content," Composites Science and Technology, Vol. 64, 2004, pp. 2363-2371. doi:10.1016/j.compscitech.2004.04.002

[12] J. Zhu, J. Kim, H. Peng, J. Margrave, V. Khabashesku and E. Barrera, "Improving the Dispersion and Integration of Single-Walled Carbon Nanotubes in Epoxy Composites through Functionalization," Nano Letters, 2003, Vol. 3, No. 8, pp. 1107-1113. doi:10.1021/n10342489

[13] M. Abdalla, P. Dean, D. Robinson and E. Nyairo, "Cure Behavior of Epoxy/MWCNT Nanocomposites: The Effect of Nanotube Surface Modification," Polymer, Vol. 49, No. 15, 2008, pp. 3310-3317. doi:10.1016/i.polymer.2008.05.016

[14] T. Zhou, X. Wang, X. Liu and D. Xiong, "Influence of Multi-Walled Carbon Nanotubes on the Cure Behavior of Epoxy/Imidazole System," Carbon, Vol. 47, No. 4, 2009, pp. 1112-1118. doi:10.1016/j.carbon.2008.12.039

[15] K. Yang, M. Gu, Y. Jin, G. Mu and X. Pan, "Influence of Surface Treated Multi-Walled Carbon Nanotubes on Cure Behavior of Epoxy Nanocomposites," Composites Part A: Applied Science and Manufacturing, Vol. 39, No. 10, 2008, pp. 1670-1678. doi:10.1016/j.compositesa.2008.07.011

[16] S. H. Kim, W. II Lee and J. M. Park, "Assessment of Dispersion in Carbon Nanotube Reinforced Composites Using Differential Scanning Calorimetry," Carbon, Vol. 47, No. 11, 2007, pp. 2699-2703.

[17] A. T. Seyhan, F. H. Gojny, M. Tanoglu and K. Schulte, "Critical Aspects Related to Processing of Carbon Nanotube/unsaturated Thermoset Polyester Nanocomposites," European Ploymer Journal, Vol. 43, 2007, pp. 374-379. doi:10.1016/j.eurpolymj.2006.11.018

[18] J. Bae, J. Jang and S.-H. Yoon, "Cure Behavior of the 
Liquid-Crystalline Epoxy/Carbon Nanotube System and the Effect of Surface Treatment of Carbon Fillers on Cure Reaction," Macromolecular Chemistry and Physics, Vol. 203, No. 15, 2002, pp. 2196-2204.
doi:10.1002/1521-3935(200211)203:15<2196::AID-MA CP2196>3.0.CO;2-U 